\title{
Celebrating Co-operation among Saskatchewan's Libraries: The Multitype Library Board, 1996-2016
}

\author{
J. Michael Shires \\ Dr. John Archer Library \\ University of Regina \\ Michael.Shires@uregina.ca
}

\section{Author Note}

Correspondence concerning this article should be addressed to J. Michael Shires, Dr. John Archer Library, University of Regina, 3737 Wascana Parkway, Regina, SK, S4S 0A2. Contact: Michael.Shires@uregina.ca

\begin{abstract}
Saskatchewan's Multitype Library Board (MLB) celebrates its 20th anniversary in 2016. It was established under the passage of the provincial government's The Libraries Cooperation Act in 1996 to facilitate the co-operative development of the multitype library system in Saskatchewan. This legislation is unique in Canada. The MLB is a Minister of Education Advisory Board and it provides a forum to promote and facilitate co-operation among over 320 public libraries in 10 provincial systems, 25 post-secondary libraries, 755 school libraries, several special libraries, and other information providers. Major milestones of the MLB include helping to eliminate the Provincial Sales Tax on library subscriptions, establishing a provincial digitization plan, and creating a cross-sector database licensing program that has resulted in a projected value of 14.8 million dollars to Saskatchewan users in 2014. The development of the MLB and the impact of the programs it has initiated will be discussed, and recommendations for developing a collaborative initiative will be provided.
\end{abstract}

\section{Keywords}

Multitype library system, multitype library board, Saskatchewan libraries, library cooperation, library partnerships

\section{Introduction}

The province of Saskatchewan has been recognized for its long-held spirit of cooperative community building since the establishment of a district government in the late 19th century. This coincided with a massive influx of immigrants who homesteaded and built new communities with libraries across a very large and sparsely populated region. For example, the town of Wolseley, Saskatchewan has claimed the status of supporting Saskatchewan's longest continuous library service when "... a library was established as part of a Farmer's Institute in 1883 before becoming the town's public library in 1912" (Kerr, 2005, pp. 12-13). The province's motto, From Many Peoples Strength, expresses 
the ethnic diversity of Saskatchewan's population and represents the long history of citizens working together ${ }^{1}$.

Collaborative efforts between libraries and the provincial government were woven tightly into the fabric of Saskatchewan's early years. This was illustrated by the provincial government-appointed public library board that operated for over 40 years starting in 1946. "The first-ever government advisory committee on libraries was the Saskatchewan Library Advisory Board" (Kerr, 2005, p. iv). New library acts were passed in 1953 and 1969, and the Saskatchewan Library Development Board had two major duties: "...to make recommendations to the minister [of Education] and to work with the provincial librarian in establishing a province-wide service” (Kerr, 2005, pp. 112-113).

Successful local and regional joint venture agreements (e.g. shared facilities and resource sharing) had existed in the province prior to the ground-breaking passage of The Libraries Co-operation Act $^{2}$ and the formation of the Multitype Library Board (MLB). However, the vision of a new multitype library system was access for all residents while sharing resources at progressively higher jurisdictions (e.g. locally, regionally, and provincially). This article examines the creation of the most unique library co-operative in Canada, assesses the impact of programs the MLB has initiated, and provides recommendations for developing collaborative initiatives.

A few definitions are needed to clarify concepts in this paper. Many readers are probably familiar with the term consortia: “....any local, statewide, regional, or interstate cooperative association of libraries that provides for the systematic and effective coordination of the resources of school, public, academic, and special libraries and information centers, for improving services to the clientele of such libraries" (Telecommunication, 2015, para. 3). However, the reading audience may not be as familiar with the word multitype. The MLB 2001-02 Annual Report defined a multitype library system as a "... network of working relationships, between any combination of autonomous libraries and information providers, established to share services and resources for mutual benefit" (Saskatchewan Multitype Library Board [Saskatchewan MLB], 2002a, p. 7). In this article, multitype is used both synonymously with consortia and as the name of Saskatchewan's multi-sector library board.

\section{Environmental Scan}

In 2013, the Saskatchewan Provincial Library and Literacy Office (PLLO) conducted an environmental scan of library consortia and related groups, particularly those in Canada, and concluded that the MLB was unique because it was the only entity that had a legislated advisory role to government, a provincial library, and the library community ${ }^{3}$. Some consortia had a significant promotional, lobbying, or advocacy component.

\footnotetext{
${ }^{1}$ In 1986 Queen Elizabeth II granted a Royal Warrant that created Saskatchewan's Coat of Arms and included the Latin motto Multis E Gentibus Vires (From Many Peoples Strength).

2 The official name is The Libraries Co-operation Act being Chapter L-14.01 of the Statutes of Saskatchewan, 1996 (effective December 31, 1996), as amended by the Statutes of Saskatchewan, 2014, cE-13.1.

${ }^{3}$ Extrapolated from a presentation done by PLLO librarian Julie Arie at a meeting of the Saskatchewan Multitype Library Board in Regina on 27 Feb. 2013.
} 
Consortia Canada listed 22 operating groups, and all appeared to be not-for-profit (Consortia Canada, 2015, para. 5). They all shared the MLB's goal of contributing to their provincial or regional jurisdiction's educational, economic, and social development. All provincial and territorial consortia offered resources and services to one or more library sectors in their jurisdictions. However, unlike the MLB, some, such as BC Libraries Cooperative and The Alberta Library, were member-driven. They relied on membership fees to provide services (interlibrary loan, licensed resources, digitization, etc.) for information providers. Others, like the Southern Ontario Library Service, received funding from the provincial government and only served the public library sector.

One noteworthy consortia that warrants mentioning briefly is Knowledge Ontario (KO):

...Formerly known as the Ontario Digital Library, it was first conceptualized in the early-2000s during consultations between the Ontario Library Association (OLA) and provincial stakeholders representing Ontario's public libraries, colleges, universities, public schools, and government ministries... a business plan for the proposed organization was submitted to the Government of Ontario and in 2004 the Ministry of Culture subsequently provided substantial funding over the next few years...KO remained an entity under OLA until its incorporation in 2006 and soon launched several resources and services such as Our Ontario, Ask Ontario, and the eResources Portal. (Wikipedia, 2015)

KO won many awards for innovation and excellence. However, funding was not sustainable, and perhaps due to an overly-ambitious strategic plan to serve all library sectors, KO ceased operations in 2012.

\section{Building Library Co-operation in Saskatchewan}

\section{Library Inquiry Committee}

The origins of Saskatchewan's MLB can be traced back to 1966. "Commissioners, appointed by Order in Council 1244/66, June 29, 1966, were tasked to prepare a report on the state of public and regional library facilities and make recommendations to the provincial government for their development and subsequent impact on communities" (Saskatchewan Library Inquiry Committee, 1967, p. ii). The Library Inquiry Committee Report that was published in 1967 was based upon comments from public hearings that took place in Saskatoon, Prince Albert, North Battleford, Kindersley, Swift Current, Moose Jaw, Yorkton, Weyburn, and Regina. The report stated that "... more than 450 people spoke and 112 briefs were read and discussed" (Saskatchewan Library Inquiry Committee, 1967, pp. 123-124). The document consisted of nine recommendations; the sixth one, titled Library Co-operation in Saskatchewan, was based upon the committee's observations that "...the people of Saskatchewan appeared ready and willing to co-operate, one library with the other, one system with the other, in providing adequate library service" (Saskatchewan Library Inquiry Committee, 1967, p. 40). The report summarized this recommendation by stating that "co-operation among university, school and public libraries leads to increased services for all segments of the population. The Provincial Library should initiate and develop avenues of co-operation 
between public libraries and other libraries" (Saskatchewan Library Inquiry Committee, 1967, p. 43). Much progress was made on other recommendations in the 1967 report such as the expansion of regional public library systems. However, developing and implementing a province-wide, cross-sector library board was more challenging.

\section{Echo Valley Library Forum}

The next significant event in the development of a province-wide library co-operative occurred in 1988. The Echo Valley Library Forum that took place in Echo Valley, SK from November 3-6, 1988 was "...the first attempt to redefine the Saskatchewan library system since the Library Inquiry Committee of 1967. It was the creation of motions passed by SLTA [Saskatchewan Library Trustees' Association] on May 1985 and the SLA [Saskatchewan Library Association] on May 1986" (Kerr, 2005, p. 238).

Organizing the Forum was a mammoth project, but months of planning resulted in a very successful event for over 100 delegates who attended. A moderator was hired to lead various themed breakout sessions. Joylene Campbell, past Saskatchewan Provincial Librarian, wrote that the event was:

... a conference in which participants representing a broad cross-section of the Saskatchewan population and different types of Saskatchewan libraries considered what Saskatchewan people might need and want from their libraries in the future...the Forum was the first step in developing a strategic plan to prepare for that future. (Foran \& Fritz, 1988, p. 133)

The Forum drafted five key issues, one of which called for a one-province library system and a shared vision. However "the limitation of the forum was that people talked together (useful) but specific recommendations had no place to go" (Kerr, 2005, p. 239).

\section{Vision: Independent...But Together}

An important action from the Forum was the striking of a Vision Committee, which drafted a publication to synthesize the published proceedings of the event. The document was titled Vision: Independent...But Together and it was co-published by SLA and SLTA in 1990. It outlined library deficiencies identified by the Forum and actions to address them in a vision for the future of Saskatchewan libraries. The Vision document boldly stated that "a confederation of public, academic, school, and special libraries could provide the new framework and the mechanisms that are needed. It could provide a forum for the discussion of library and information issues on a provincial scale across traditional jurisdictions" (Hamre, Jenkins, \& Sagal, 1990, p. 6).

Successful elements in the proposed province-wide system were identified: autonomy; formal co-operation; patron access; needs assessment; planning and development; resource sharing; communication; and funding. Twenty-one stakeholders, including library associations, provincial government, academic, public, school, and special libraries, were listed as supporting the Vision document. Significantly, the word multitype was used, seemingly for the first time, in a published library document in Saskatchewan. The Vision report concluded that "A Province-Wide Multitype Library 
System can only be achieved if individuals in all library systems are willing to work together to make it happen" (Hamre, Jenkins, \& Sagal, 1990, p. 10).

\section{Think Globally...Search Locally}

The impetus for a multitype library system in Saskatchewan started to gain traction in the early 1990s. SLA helped secure a grant from SaskCulture and the provincial government struck a new province-wide vision action committee that

...consulted with potential partners and stakeholders and developed the 1990 vision into a plan. Independent But Together: A Vision for a Province-wide Multitype Library System was published in 1992 as a result of these consultations...The Minister's Multitype Library Development Advisory Committee was appointed by the Minister of Municipal Government, in April 1994 [and]...it was asked to develop a strategic plan for the implementation of a multitype library system for the province of Saskatchewan and to provide a mechanism to communicate multitype library development strategies to member organizations, stakeholders and the broader community. (Minister's Multitype Library Development Advisory Committee, 1996, pp. 3-4)

Months of committee work resulted in the PLLO publishing a landmark document in 1996 titled Think Globally... Search Locally: A Strategic Plan for the Implementation of a Multitype Library System in Saskatchewan.

The report had several goals, strategies, and funding principles that addressed issues raised in the 1988 Echo Valley Library Forum Proceedings in order to guide the longterm development of a province-wide multitype system. Think Globally...Search Locally contained a detailed framework based upon earlier proposals:

...to support communities in their access to affordable, quality information services...the nature of the network of working relationships was...to facilitate sharing across jurisdictional, institutional and political boundaries...defined working relationships to include...formal and informal agreements, protocols, services, funding, standards and structures. (Minister's Multitype Library Development Advisory Committee, 1996, p. 3)

The document also recommended a 15-member multitype board to represent various types of library sectors and associations. The report was "...created by consensus which consumed time early on, so it had a sense of how partners were different - in roles, clients, size, structures - but shared common needs" (Kerr, 2005, p. 240).

\section{The Libraries Co-operation Act}

Passage of The Libraries Co-operation Act in 1996 was a culmination of many years of stakeholders from all library sectors strategizing and publishing proposals for a province-wide multitype system. The act has been the only government-legislated cooperative of libraries in Canada. Its purpose was taken largely from the aforementioned Think Globally... Search Locally document. The PLLO was mandated to administer the 
act and a key piece of this legislation was the establishment of a new Minister of Education Advisory Board, more commonly known as the MLB.

The Libraries Co-operation Act was not passed in isolation; Saskatchewan's The Public Libraries Act was passed in the same year. The simultaneous passage of both acts has reflected the desire of Saskatchewan's citizens to have strong and co-operative province-wide library services. Recent library sector statistics in Saskatchewan are as follows: more than 320 public libraries ${ }^{4}$ in 10 library systems ${ }^{5} ; 25$ post-secondary libraries $^{6}$; 755 school libraries $^{7}$; several special libraries and other information providers; and the PLLO.

Saskatchewan's Ministry of Education website states that the PLLO was entrusted, through the latter act, to coordinate the province-wide public library system. The Ministry's website says that the PLLO would fulfil this role by developing province-wide library policies, maintaining an electronic library information network, co-ordinating resource sharing activities, and providing cost-effective centralized services. Efforts of these projects are illustrated by the fact that “....all municipalities are required, by law, to participate and thus provide library services...Saskatchewan, with SILS [Saskatchewan Information \& Library Services Consortium], now has a single computer platform, a single bibliographic database, common policies, and one public library card" (Campbell, 2014, p. 1).

\section{Developing the Multitype Library Board}

\section{Structure}

The MLB was mandated to make library-related policy recommendations to Saskatchewan's Minister of Education. The board was intended to represent the best thinking on multitype-related issues and establish model multitype agreements but not to advocate on behalf of sectors. Consensus decision-making would be a cornerstone principle of the multitype system and MLB members would not be asked to agree to anything contrary to the mandate of the organization or sector they represent. Individuals would consult with their sectors to ensure a broad understanding of all sectors' needs and enable participation of all information providers in multitype initiatives. The Libraries Co-operation Act outlined the board's communication and

\footnotetext{
4 This figure is from a 2015 Wapiti Regional Library System public service message, running from September 17 to 25 , stating that all public libraries in Saskatchewan will be migrating to a new library catalogue system.

${ }^{5}$ This number from Saskatchewan Libraries breaks down the 10 provincial systems into 7 regional libraries (Lakeland, Wapiti, Wheatland, Parkland, Chinook, Palliser, Southeast), 2 municipal libraries (Regina and Saskatoon), and a northern library system (Pahkisimon Nuye?áh) that is a federation of 11 northern community public libraries and has the legislated mandate to act as the central library for northern Saskatchewan.

${ }^{6}$ This figure from the Government of Saskatchewan includes universities, federated colleges, affiliated colleges, Saskatchewan Polytechnic, Aboriginal and northern education, regional colleges, and career colleges. It excludes private, vocational, or career colleges.

7 The figure, based on the assumption that each Saskatchewan school has a resource centre or library, is from Active List of Saskatchewan Schools/Programs Provincial K-12 Enrolment (as of September 30, 2014).
} 
reporting by stating that the MLB “...meet at least three times during each government fiscal year (April 1 to March 31)...submit its annual report to the Minister of Education to be tabled in the Legislature...[and] provide communication and public awareness services for the development of the multitype library system" (Government of Saskatchewan, 1996, pp. 5-7).

The act defined MLB representation by stating that board member terms of office would be two years with no more than two consecutive terms, and that staff from PLLO would provide administrative support and act as Board Secretariat (later renamed Multitype Development Unit). All members would be appointed by the Minister of Education to represent various sectors. Four directors would be appointed from the following systems: individual public library or public library system, school library or school library system, post-secondary library or post-secondary library system, and an individual special library or special library system. Three individuals would also be chosen from a list of persons nominated by SLA, SLTA, and the Saskatchewan School Boards Association (SSBA) to represent their respective associations. Additionally, one other person employed in any capacity by a post-secondary library and one person by a special library would be appointed. Finally, the minister could also appoint an individual who was employed by any information provider, a person from the Saskatchewan Urban Municipalities Association (SUMA), and one or two other persons (in consultation with SUMA and the library community respectively). See figure 1 for a graphical representation of the MLB's composition.

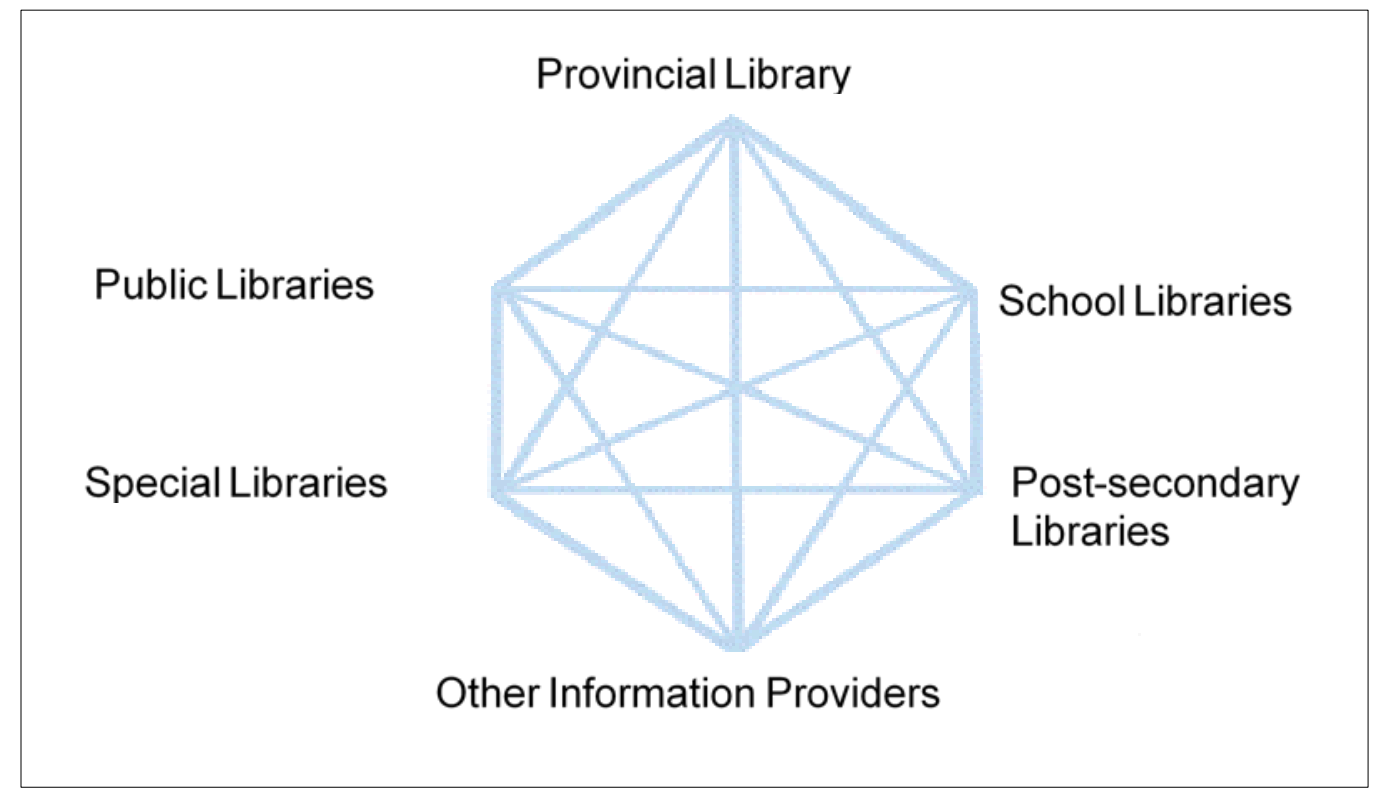

Figure 1. Six sectors represented on the MLB. Adapted from Saskatchewan Multitype Library Board. (2010). A three year strategic plan 2010-2013. Regina, SK: Saskatchewan Multitype Library Board. Copyright 2010 by the Saskatchewan Multitype Library Board. 


\section{Identity and Strategic Plan}

Much work lay ahead after passage of The Libraries Co-operation Act. Each sector needed to send a list of nominees to the provincial government. Eleven individuals were appointed in 1998 and the MLB held its inaugural meeting in Regina in March 1999 (Saskatchewan MLB, 1999, para. 1-3). An individual was also hired to facilitate the board's initial strategic planning session during the two-day meeting. A chair was elected, board operations were discussed, projects identified, and subgroups established. All work shared an underlying theme of promoting the MLB and showcasing the value of libraries as integral to the province's knowledge economy.

Future MLB meeting agendas would include sector reports, project status updates, and guest speakers. Three high-ranking government officials representing Municipal Affairs, Culture, and Housing made presentations about funding and structural options (Saskatchewan MLB, 2000). They expressed interest in the evolving role and tasks of the MLB and commended members for their role in coordinating cooperative activities among Saskatchewan libraries.

The MLB developed a logo and tagline to brand itself and help frame its strategic plan (see figure 2). In 2003, it published a second strategic plan. Performance indicators were added to the four strategic directions from the first plan that more effectively connected long-term objectives. A third strategic plan was drafted in 2010 that aligned more closely with the Ministry of Education's strategic priorities. The MLB has long upheld core values of

...strong local autonomous library partners working together... [to] create a capacity for library service that is broader, more effective, and less costly than the partners could achieve individually; ...commitment to co-operation for mutual benefit: growth and development of multitype initiatives...realized through people voluntarily working at the local level to develop what works for them;...continued effort is required to build a strong multitype library system...[and] remain a high priority for each of the partners and it may mean marshalling resources to ensure that the system remains healthy as it develops; ...address the changing needs of an aging population, the rural/urban shift, an increase in First Nations and Métis people and the widening literacy divide in Saskatchewan;... recruitment, retention and training [of] qualified staff."

\footnotetext{
${ }^{8}$ MLB values in strategic plans have evolved over the years and are listed in various documents.
} 


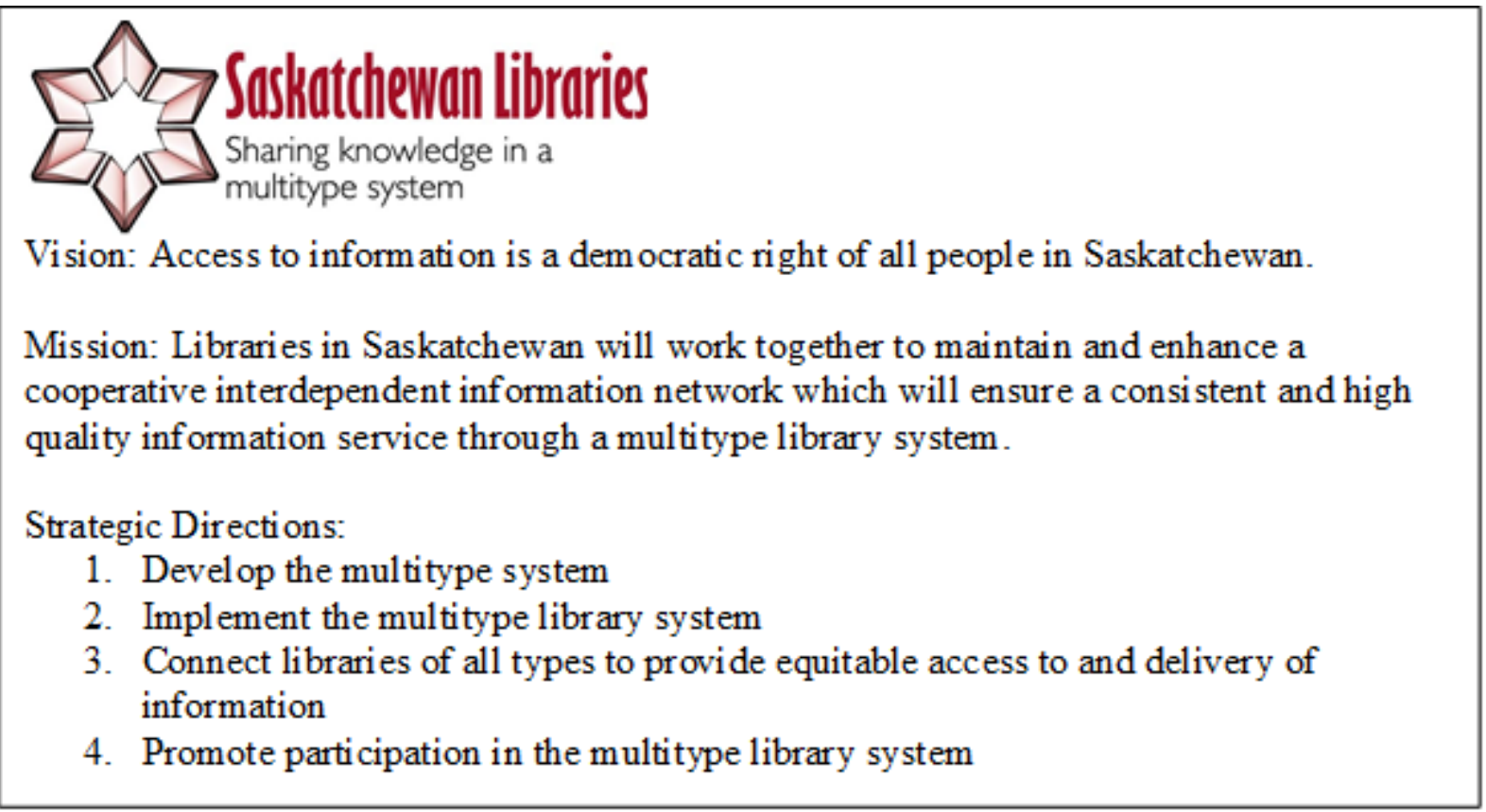

Figure 2. MLB in 2003. Adapted from Saskatchewan Multitype Library Board. (2003). The Saskatchewan Multitype Library Board strategic plan update. Regina, SK: Saskatchewan Multitype Library Board. Copyright 2003 by the Saskatchewan Multitype Library Board.

\section{Multitype Library Board Milestones}

\section{Timeline}

The MLB has investigated many issues facing all library sectors in Saskatchewan and provided recommendations for co-operative improvements in published background papers and reports. A list of significant accomplishments illustrates the number of projects the MLB has initiated ${ }^{9}$ (see Appendix A for a comprehensive chronological list).

- Published a report by the Multitype Database Licensing Working Group titled Province-wide Database Licensing: A Project to Research Licenses to Commercial Information Databases for All Types of Libraries in Saskatchewan that led to establishing the MDLP in 1999

- Published Usage of Electronic Document Delivery Services in Saskatchewan Libraries after surveying Saskatchewan libraries to gather information about their use of and opinions on electronic document delivery systems

- Established Saskatchewan Libraries Education Bursary with seed money from the PLLO

\footnotetext{
${ }^{9}$ Highlights of selected accomplishments were taken from various MLB sources.
} 
- Published Saskatchewan Libraries Working Together: A Discussion Paper, which was revised in 2005. Identified emerging issues and recommendations for potential solutions and profiled the value of libraries and information providers

- Published Creating a Representative Library Workforce in Saskatchewan, a report to encourage a strategy for promoting a representative library workforce in the province

- Published Working Together: Saskatchewan Libraries and Other Information Providers as a revision of Saskatchewan Libraries Working Together: A Discussion Paper (2002)

- Established the Saskatchewan Digital Alliance (SDA), a cross-sector group with representatives from libraries and archives to further province-wide digitization

- Worked with the Ministry of Finance and PLLO to eliminate the Provincial Sales Tax on library subscriptions for print and online newspapers, journals, magazines, and reference books

- Ensured access to MDLP Core Collection for all First Nations schools in Saskatchewan

- Coordinated the Sask History Online digitization project

- Coordinated a province-wide One Book, One Province initiative

\section{Communications Strategy}

Establishing meaningful two-way communication between the MLB and the various sectors that it represents has been a high priority. The board needed to "...reach governments, other decision-makers, the library community, as well as business, rural, and educational audiences... and help foster an understanding of the benefits of greater cooperation among libraries and what a multitype library system would mean to Saskatchewan people" (Saskatchewan MLB, 2000, para. 7). The MLB distributed promotional literature to many library associations across Saskatchewan and Canada, and in 2001 it struck a public relations committee to develop strategies to promote the value of libraries to Saskatchewan residents. The committee was involved in many projects and published a report in 2002. The report's five recommendations were to hire additional PLLO staff for MLB administrative support, offer locally-run promotions workshops, provide more education and training opportunities, develop the MLB website, and support tools development. All recommendations have been implemented, are reviewed regularly, and have contributed to the MLB's success.

\section{Multitype Database Licensing Program}

"The Multitype Database Licensing Program (MDLP) is the primary and longest running program of the board" (Saskatchewan MLB, 2015a, p. 4). An early initiative by the MLB was establishing a Multitype Database Licensing Working Group, which in turn 
published a report in 1997 titled Province-wide Database Licensing: A Project to Research Licenses to Commercial Information Databases for All Types of Libraries in Saskatchewan. Recommendations from the report led to establishing the MDLP in 1999 and a MDLP Committee to administer the program's core collection of licensed databases. Any library in Saskatchewan could join the MDLP by contributing funds and gaining access to consortially licensed online resources. PLLO has provided administration for all licenses and has led a committee representing all library sectors to develop policies and recommendations related to the program. The MDLP's first AGM was held in 2002 and it soon became part of the MLB's AGM. The amalgamation provided an opportunity for program participants to review accomplishments and strategize future activities, and it allowed individuals to meet with MLB members and to learn about board initiatives.

In 2001, Saskatchewan was the only jurisdiction in Canada that had achieved database licensing for all provincial residents in all ten public library systems and many school libraries (Saskatchewan MLB, 2002a, p. 12). Several post-secondary and special libraries have also participated in the MDLP. A significant accomplishment of the MDLP occurred in 2010 when all First Nations schools in Saskatchewan finally had access to the core collection. Schools were under federal government jurisdiction, so much negotiating was needed to reach agreements with vendors (Saskatchewan MLB, 2002a, p. 9).

In 2009-10, the MDLP established an opt-in supplemental collection for core collection members. The PLLO could negotiate licences for MDLP members from at least two sectors that were willing to participate. The collection has grown in the number of partners and databases while the PLLO has respected budgetary issues with partners and negotiating licenses of interest to a diverse group. A subcommittee of MDLP members from each library sector has been formed to create product evaluation forms and surveys. The MDLP will also start developing outcome measures to complement outputs and usage statistics.

Since its inception, the MDLP has been the flagship program of the MLB. Many library workers know about the MLB primarily through its work with establishing and maintaining the program. A recent survey found that $87 \%$ of MDLP end-users were satisfied or very satisfied with the quantity and quality of licensed databases (Saskatchewan MLB, 2015a, p. 10). A unique characteristic of the program is that it has no sector-based funding formula for cost-sharing of the core collection. Information providers from all sectors contribute based on what their financial situation allows ${ }^{10}$. This voluntary process means that the return on investment for contributions and usage in all sectors is not equal (see Table 1).

${ }^{10}$ As of December 2015, the MDLP Core Collection contained 31 resources. 
Table 1. 2011-12 MDLP Contributions and Searches by Sector ${ }^{11}$

\begin{tabular}{|c|c|c|}
\hline Partner & $\begin{array}{c}\text { Financial Contribution } \\
\text { Percentage }\end{array}$ & $\begin{array}{c}\text { Database Searches } \\
\text { Percentage }\end{array}$ \\
\hline $\begin{array}{c}\text { Ministry of Education } \\
\text { (PLLO) }\end{array}$ & 14 & 0 \\
\hline Post-Secondary & 19 & 63 \\
\hline $\begin{array}{c}\text { School (Ministry of } \\
\text { Education) }\end{array}$ & 29 & 26 \\
\hline Public & 30 & 3 \\
\hline Special & 8 & 8 \\
\hline
\end{tabular}

The PLLO maintains a licensing fund to help ensure the sustainability of the MDLP. In 2013, the PLLO "...conducted a program review of the MDLP, as required for all programs under the Government of Saskatchewan's Growth and Financial Security Act. The review reaffirmed the natural alignment between the Ministry of Education's objectives and the resources provided by libraries through the program" (Saskatchewan MLB, 2013, para. 26).

The MDLP has been very successful, particularly with libraries in small or remote communities that struggle with scarce collection development resources. The program has contributed to more equitable access to reliable licensed content for all Saskatchewan residents. The most recent MLB annual report stated that

at a total cost of $\$ 623,144$, the MDLP Core Collection provided an excellent return on investment $(\mathrm{ROI})$ throughout 2014 . The total projected value that the MDLP Core Collection provides to Saskatchewan users is $\$ 14,876,444$. This figure is derived from commonly used price-per-article (\$25 per article value) and price per-newspaper issue (\$2 per newspaper value) dollar amounts. (Saskatchewan MLB, 2015a, p. 7)

\section{Saskatchewan Digital Alliance}

The Saskatchewan Digital Alliance's (SDA) origins can be traced to 2003 when directors of the six largest libraries in Saskatchewan and the Saskatchewan Archives Board published and submitted to the MLB a discussion paper titled Fostering Digitization Initiatives in Saskatchewan. The MLB agreed with the report's recommendation to draft a province-wide digitization strategy. Discussion forums, surveys, and follow-up reports took place over the next few years, and in 2005 a report titled Digitization in Saskatchewan and Critical Issues in its Continued Development was published. It proposed the formation of a co-operative digital alliance to support organizations involved in digitization and lead the development of digitization expertise and best practices.

\footnotetext{
${ }^{11}$ Latest available data were extrapolated from charts in the Annual report 2011-12 Saskatchewan Multitype Library Board.
} 
Digitization projects around the province were soon established. The first multi-sector digitization project was called Our Legacy. It contains thousands of records from various cultural and heritage collections and repositories, including material relating to First Nations, Métis, and Inuit peoples. A second project was called the Saskatchewan War Experience, a digitized collection of photos, documents, published materials, sound, film, and other formats from many institutions that captured Saskatchewan's experience with war. Due to its experience with digitization and extensive resources, the University of Saskatchewan played a lead role in these two projects. The University of Regina received a grant for a digitization project called Saskatchewan's Visual Arts, which explores the connection between the creation of the Saskatchewan Arts Board in 1948 and the arts movement beginning in 1950.

\section{Sask History Online}

In 2012, a large three-year grant was awarded by the Ministry of Education to the University of Saskatchewan. It enabled the creation of a digitized searchable collection of photographs, videos, audio, and textual materials like letters, books, and diaries from galleries, libraries, archives, museums, and other cultural institutions across the province. Due to past digitization work, the University of Saskatchewan had the capacity to work with the SDA and develop the project proposal and help draft a long-term strategic plan. The MLB expressed its full support and recommended that the Ministry of Education approve the project charter that was soon named Sask History Online (SHO).

Many information providers and memory institutions in Saskatchewan were invited to provide content to $\mathrm{SHO}$ and help build a digital collection of cultural and historical items. Previously digitized collections, including the Saskatchewan War Experience, were moved into the repository. The SHO project completed its original mandate when funding ended in 2014. The result of 9,597 hours of digitizing, the repository was 4.2 terabytes in size and contained approximately 250,000 records from over 60 contributors as of February 2015 (Saskatchewan MLB, 2015b). Funding sources are being explored to start new projects such as digitizing newspapers from rural communities.

\section{Maureen Woods Education Bursary}

The Saskatchewan Libraries Education Bursary, renamed the Maureen Woods Education Bursary in 2013, was established by the MLB in response to cross-sector concerns about librarian recruitment and retention. SLA was asked to be a partner and administer the bursary. The PLLO provided $\$ 100,000$ in seed money between 2002 and 2008 to establish the bursary. It has been offered annually by SLA since 2003 to assist one student obtaining a Master of Library and Information Science degree from an American Library Association accredited program and find post-graduation employment in Saskatchewan. Many award recipients have settled in Saskatchewan and become actively involved in the profession. 


\section{Multitype Library Board Present Day}

Saskatchewan Libraries
Vision: Successful communities
through library co-operation.
Mission: Through communities through library cooperation.
of citizens of Saskatchewan.
Strategic directions:
1. Engage strategic partners in the continuing dev elopment of the multitype library
system
2. Identify opportunities for co-operation in order to address em erging issues
3. Initiate mechanisms for co-operation

Figure 3. MLB in 2015. Adapted from Saskatchewan Multitype Library Board. (2015). Annual report 2014-2015 Saskatchewan Multitype Library Board. Copyright 2015 by the Saskatchewan Multitype Library Board.

\section{Board Composition}

As of February 2015, the MLB was comprised of 13 members: one representative each from Aboriginal Libraries, Archives, SLA, SSBA, SLTA, and Saskatchewan School Library Association (SSLA); two representatives each from Special Libraries, Public Libraries, and Post-Secondary Education Libraries; and the Provincial Librarian (Saskatchewan MLB, 2015b). Administrative support from the PLLO included the Director, Library Accountability and Administration, and two Multitype Library Service Coordinators. Between 2000 and February 2015, 58 individuals have held the distinction of being appointed by the Government of Saskatchewan to represent an information provider sector on the MLB ${ }^{12}$.

\section{Multitype Library Training and Promotion}

In 2015, a Multitype Library Training and Promotion Committee was established by the MLB. Its mandate is to guide the MLB and Multitype Development Unit to develop library staff training and provide social media messages (primarily through Twitter) about MDLP and SHO resources. One project is to create a province-wide training series using Adobe Connect. Sessions would be designed for library workers and focus on MDLP and SHO resources. Training would be presented by Multitype Development

12 Content was extrapolated from Past Multitype Library Board members 2000-2005. The number excludes current members. Some individuals have represented different sectors at different times and thus were counted once. 
Unit staff and guest presenters. As of January 2016, six webinars have been offered and have been archived in the Library Toolshed ${ }^{13}$.

Another MLB initiative was a successful bid to join the Library Toolshed, a collaborative initiative developed by The Alberta Library and the BC Libraries Cooperative. The Library Toolshed is a digital learning object repository and a site where library staff can access training, instructional, and programming resources created by their peers. Membership allows staff from any information provider in Saskatchewan to upload content to the Library Toolshed.

The Multitype Library Training and Promotion Committee also put out a call for libraries to submit short anecdotal success stories that illustrate staff from Saskatchewan demonstrating MDLP or SHO resources to patrons. The project is called Eureka! I found it and stories will be added to the Library Toolshed and also integrated into the aforementioned Adobe Connect training sessions. The committee also created and uploaded to the Library Toolshed an e-resource social media kit that provides tips and ready-made tweets for libraries to reuse to promote e-resources. A session about these projects will likely be scheduled at the 2016 Saskatchewan Libraries and Multitype 20th Anniversary Conference in Saskatoon.

\section{Saskatchewan eBooks}

After consultations with the Saskatchewan Publishers Group and library representatives, the MLB approved the Saskatchewan eBooks Initiative. The initiative will create a mechanism for Saskatchewan titles to be included in the Saskatchewan eBook Collection, and work with publishers toward contracts to allow these titles to be converted to EPUB 3 format. This project aims to overcome barriers to e-book conversion and increase Saskatchewan content available in the province's libraries. Titles will be made available to all MDLP partners and also placed in the National Network for Equitable Library Services collection.

\section{One Book, One Province}

The one book movement has been popular in North America for many years. The first province-wide program was One Book Nova Scotia, which began in 2012. By encouraging adults in the province to read the same book, the program aimed to foster a love of reading and a sense of unity, and to encourage discussion and excitement about the work (One Book Nova Scotia, 2015).

In spring 2015, the MLB surveyed several libraries in Saskatchewan to assess their interest in developing a similar project. Creating a one book program would require a high level of commitment from many library sectors, literacy groups, and community organizations. The MLB believes that this program will benefit Saskatchewan residents by encouraging reading, supporting a reading culture, increasing literacy, creating opportunities for residents to increase social engagement in their community, and

\footnotetext{
13 Six webcasts (Research in Context, LegalTrac, Sask History Online, Business Collection, Canadian Research Index, Health and Wellness Resource Centre) are archived in the Library Toolshed.
} 
promoting the value and raising the profile of libraries and literacy organizations. The MLB would like a one book program to consist of province-wide events (e.g. author readings, film screenings, musical programs, cooking programs, crafts, etc.) that relate to the content of the book.

\section{Assessing Success and Challenges}

As discussed in this article, the MLB has had many successes. Most notably, a significant financial impact was made via the formation of MDLP and its work to eliminate the Provincial Sales Tax on library subscriptions. Both initiatives have saved information providers and tax payers millions of dollars. The Education Bursary is one of the most unique for library and information management graduate students in Canada because it strengthens the library workforce in Saskatchewan. There have been 13 recipients and a majority are working in the province. Collaborative digitization efforts across the province have increased significantly since the establishment of the SDA and the subsequent development of SHO. The latter has created digitization expertise in Saskatchewan and is a rich resource that showcases the cultural history of the province.

The MLB has also faced challenges. A prominent one, largely due to the proliferation of technology, is the efficacy of the board's communications plan. Due to legislation, the board is not permitted to advocate or lobby. Other library organizations in Saskatchewan, like SLTA, have advocated actively. The MLB has published minutes and communiqués of all its meetings and submitted annual reports to be tabled in the Saskatchewan Legislature. Other reports and background papers have been published due to board and external requests. Electronic newsletters are published regularly by the Multitype Development Unit and distributed to board members. However, as a legislated body the MLB is not permitted to have social media accounts or one collective email account. The board, as a whole, cannot be contacted directly. The MLB must rely on members to send information items to their respective sector and in turn solicit feedback.

The MLB has accomplished much for residents of Saskatchewan, but many of its projects are not widely known within and outside the information provider community. Synthesizing recent accomplishments and raising awareness of new challenges in a document similar to 2005's Working Together: Saskatchewan Libraries and Other Information Providers may help promote the MLB's profile. The Libraries Co-operation Act allows for additional members to be appointed to the MLB. This includes entities like SUMA, which had representation on the board many years ago, and the Saskatchewan Association of Rural Municipalities (SARM), to which an invitation could also be given. Extending current invitations to both associations might be advantageous because their goals of improving the quality of life in urban and rural communities are similar to those of the MLB.

There are other communications strategies the MLB could pursue. The board could approach information providers in all sectors about MLB's branding co-existing in hardcopy or online formats. Board members have presented about the MLB at national and provincial conferences. Perhaps this can happen at the local level by partnering 
with library, cultural, and community groups at targeted events. Having a stronger public presence may strengthen citizens' sense of the MLB as a partner with the majority of information providers in the province and offering several resources and services.

\section{Recommendations for Developing a Collaborative Initiative}

Based upon the success of the MLB in Saskatchewan, recommendations can be made for those who are considering developing a similar kind of collaborative initiative or who work in systems that they would like to strengthen. Several institutions or like-minded groups should share some common values, face similar challenges, and recognize differences with building a partnership.

\section{Board Operations}

The MLB follows standard board operations protocol that new or existing collaborative groups could adopt. The board does not follow specific rules of order. The MLB has successfully relied on consensus building and face-to-face majority voting to pass initiatives, and on forming ad hoc committees. Larger consortia should draft a handbook that documents operations, terms of reference, policy, etc. A Chairperson, Vice-Chair, and a Secretary can be chosen by an open vote or secret ballot at the first meeting of the fiscal year or a new calendar year. Position term lengths ideally should not be tied to location and meeting frequency, and locations need to be confirmed. Depending upon the size of the board, calls for agenda items should be sent a month or two prior to board meetings. The Multitype Development Unit prepares a draft and meets with the Chair to prioritize items, suggest project timelines, and finalize the agenda. Agendas, documentation, and any member absences should be emailed well in advance of meetings. Conference calls should be available for individuals who are unable to travel.

\section{Communications}

For a consortium to remain relevant, maintaining two-way communication to identify mutual needs and challenges and to find solutions among board members and their respective sectors is crucial. A board that conceives of and initiates projects with little or no consultation with stakeholders will operate in a vacuum and likely not survive. There is no specific process that MLB members follow to consult with their sectors. Individuals are responsible for informing their sectors in the best manner possible. The most popular flow of information (e.g. forwarding e-newsletters, board meeting communiqués, and minutes published by the Multitype Development Unit) to key contacts at institutions is likely via email, face-to-face discussions, and updates at sector-based information provider board meetings. An operational board should entice individuals to want to join. In a time of volunteer deficits, being a representative should offer some prestige and provide opportunities for meaningful discussion with others, partaking in exciting project work, and having fun.

\section{Planning}

Much time is required to create or strengthen an existing partnership, but the payoff can be very beneficial. If starting anew, scheduling consultations with stakeholders is 
recommended to help assess the current environment, identify challenges, and find common ground for solutions. Publishing an ad hoc committee report or position paper that also identifies those with the authority to take action can ease the possible labour of drafting a strategic plan. Having a clear vision, mission, and key actions can help prevent the impulse toward too many ambitious goals.

Staff in the Multitype Development Unit have experience with drafting meeting agendas and recommending priorities for planning initiatives. However, board members are responsible for approving new projects, deciding if an ad hoc committee should be established or if a sector(s) should take the lead, and informing their sectors. In a recent example, the board approved a new One Book, One Province initiative and decided that SLA was the logical province-wide and member-driven organization to approach. Next, the board member representing SLA had to contact that association's board, provide the background, and decide if there was capacity to implement the project.

\section{Funding}

With access to a large pool of government seed money, one library sector or one institution can greatly assist in planning a collaborative initiative. However, having startup funds will not guarantee a sustainable consortium. The unfortunate demise of KO seems to prove this. Identifying a few key projects that have measurable outcomes across many sectors or institutions would be beneficial. More complex initiatives that require a funding model may include drafting an RFP for a shared ILS or creating and administering a licensing fund for subscribed resources.

Voluntary member contributions to manage a consortial licensing program are worth exploring. In Saskatchewan, while this voluntary process has meant that the return on investment for contributions and usage in all sectors has not been equal, few institutions have left the MDLP. However, for the MDLP Committee to prevent the complicated alternative of a sector-based funding formula, some licenses will need to be revisited if financial contributions cannot support the MDLP.

\section{Conclusion}

Saskatchewan's multitype library system is a unique partnership in Canada. It is the byproduct of Saskatchewan residents working together toward a common goal. Between 1966 and 1996 many information providers, related professional associations, community groups, and key public library trustees, library directors, and politicians strategized and built momentum for the establishment of a multi-sector group to coordinate planning and implementing province-wide resources and services. That 30year time period was bookended by the provincial government initiating the Library Inquiry Committee and passing The Libraries Co-operation Act.

The MLB continues to review its many accomplishments in order to advance the multitype library system for the benefit of all residents in Saskatchewan. As indicated in past MLB documents and, most recently, the MLB's 2014-15 Annual Report, the board has continuously reinforced the notion that libraries are among the most cost-effective investments in the future of the province. "Multitype service is the most recent example 
of the Saskatchewan library system working at its best - cooperative, innovative, sophisticated" (Kerr, 2005, p. 242). However, to remain successful and relevant, twoway communication with MLB members and their library sectors needs to be upheld in order to identify mutual needs and challenges and find solutions. The MLB's consortial model features representation from strong local autonomous library partners, high involvement in consensus decision-making, and the mutual benefits of co-operation. These are important values that will contribute to the long-term sustainability of an effective collaborative group.

* The author wishes to thank Regan Gunningham for her assistance with this article.

\section{References}

Alberta Library \& The BC Libraries Cooperative. (2015). The Library Toolshed.

Campbell, J. (2014, May). Frances Morrison lifetime achievement award for understanding service to Saskatchewan libraries. Acceptance speech given at the 2014 Saskatchewan Libraries Conference, Temple Gardens Mineral Spa and Resort, Moose Jaw, SK.

Campbell, J. (1988). Executive summary. In B. Foran \& L. Fritz (Eds.). Echo Valley library forum, November 3-6, 1988: Proceedings (pp. 133-135). Regina, SK: Saskatchewan Library Association.

Consortia Canada. (2015). Member consortia.

Government of Saskatchewan. (1996). The Libraries Co-operation Act. Regina, SK: Queen's Printer.

Hamre, K, Jenkins, M., \& Sagal, K. (1990). Vision: Independent...but together. Regina, SK: Saskatchewan Library Association and Saskatchewan Library Trustees Association.

Kerr, D. (2005). A book in every hand: Public libraries in Saskatchewan. Regina, SK: Couteau Books.

Minister's Multitype Library Development Advisory Committee. (1996). Think globally... Search locally: A strategic plan for the implementation of a multitype library system in Saskatchewan. Regina, SK: Saskatchewan Provincial Library.

One Book Nova Scotia. (2015). Frequently asked questions.

Saskatchewan Libraries Trustees' Association. (2015). History of public library development in Saskatchewan. 
Saskatchewan Library Association. (2015). Maureen Woods education bursary.

Saskatchewan Library Inquiry Committee. (1967). Library service in Saskatchewan: The report of the library inquiry committee (a survey with recommendations) August, 1967. Regina, SK: Queen's Printer.

Saskatchewan Ministry of Education. (2015). Provincial library and literacy office.

Saskatchewan Multitype Library Board. (2015a). Annual report 2014-2015 Saskatchewan multitype library board.

Saskatchewan Multitype Library Board. (2015b). Meeting summary February 5, 2015.

Saskatchewan Multitype Library Board. (2013). Meeting summary May 28, 2013.

Saskatchewan Multitype Library Board. (2012). Annual report 2011-2012 Saskatchewan multitype library board.

Saskatchewan Multitype Library Board. (2011). Annual report 2010-2011 Saskatchewan multitype library board.

Saskatchewan Multitype Library Board. (2002a). Annual report 2001-2002 Saskatchewan multitype library board.

Saskatchewan Multitype Library Board. (2002b). Multitype library board public relations committee report to the board.

Saskatchewan Multitype Library Board. (2000). January 2000 communiqué.

Saskatchewan Multitype Library Board. (1999). March 1999 communiqué.

Telecommunication, 47 e-CFR $\$ 54.500$ (2015).

University of Regina. (2012). Saskatchewan's visual arts.

University of Saskatchewan. (2015). Sask History Online.

University of Saskatchewan. (2011). Saskatchewan War Experience.

University of Saskatchewan and Pahkisimon Nuye?ah Library System. (2008). Our legacy.

Wikipedia. (2015). Knowledge Ontario. 


\section{Appendix A: Chronological list of MLB Accomplishments}

- 1997

o Multitype Database Licensing Working Group published a report titled Province-wide Database Licensing: A Project to Research Licenses to Commercial Information Databases for All Types of Libraries in Saskatchewan that led to establishing the MDLP

- 1998

o Members of the first MLB appointed

- 1999

o First MLB meeting held

o Published Usage of Electronic Document Delivery Services in Saskatchewan Libraries after surveying Saskatchewan libraries to gather information about their use of and opinions on electronic document delivery systems

o Began regularly conducting education and awareness activities at SLA's annual conference and other venues and became a major sponsor of SLA's conference

o Established Multitype Database Licensing Program (MDLP)

- 2001-02

o Negotiated first MDLP licensed resource (EBSCO's Canadian News Source)

o Established initial seed money of $\$ 5,000$ for the Saskatchewan Libraries Education Bursary for 1 student in a graduate program for library and information management

o Published first stand-alone MLB annual report (2001-02); previous reports were included in the Department of Municipal Affairs, Culture and Housing Annual Reports

o New independently managed MLB website where documents such as minutes, communiqués, papers, and reports can be posted

- 2002-03

o Published Saskatchewan Libraries Working Together: A Discussion Paper and revised in 2005. Identified emerging issues and recommendations for 
potential solutions and profiled the value of libraries and information providers

- Archivist and aboriginal librarian became regular board appointments representing the sector of other information providers

o Established framework that enabled PLLO to administer a MDLP licensing fund

- Published report Creating a Representative Library Workforce in Saskatchewan to encourage a strategy for promoting a representative library workforce in the province

o Recommended implementing a remote patron authentication system and resource sharing system to better access MDLP licensed resources

- Established a highway sign symbol for libraries in advance of the province's 2005 Centennial Enhanced Signing Program

- 2004-05

o Developed a province-wide library promotion campaign to celebrate Saskatchewan's centennial (e.g. common slogan, key messages, promotional products, and other promotional resources that libraries province-wide could use)

- 2005-06

o Multitype Library Development Unit established with dedicated PLLO staff to provide administrative support to the MLB

o Published Working Together: Saskatchewan Libraries and Other Information Providers. Revision of Saskatchewan Libraries Working Together: A Discussion Paper (2002)

- 2006-07

o Established the Saskatchewan Digital Alliance (SDA), a cross-sector group with representatives from libraries and archives to further provincewide digitization.

o Enhanced the MDLP by working with the Ministry of Finance and PLLO to eliminate the Provincial Sales Tax on library subscriptions for print and online newspapers, journals, magazines, and reference books 
- 2008-09

- Supported Saskatchewan Information and Library Services (SILS) Consortium to apply for funding for training of a single integrated library system and for MDLP resources

- 2009-10

o Participated in Provincial Panel on Student Achievement and contributed feedback in response to the Panel's document Building for Student Success: A Guide for Focused Conversations with the Provincial Panel on Student Achievement. The Board identified the role played by libraries in six foundational components and highlighted documented research demonstrating the link between well-stocked, professionally-staffed school libraries and student achievement.

- All First Nations schools in Saskatchewan given access to MDLP Core Collection

o Opt-in MDLP Supplemental Collection established

- 2011-12

o Coordinated establishing the Sask History Online digitization project

- Created online interactive timeline of Saskatchewan libraries cooperation

o Launched Saskatchewan eBooks Initiative to increase Saskatchewan content in the electronic collections of the province's libraries

- 2013-14

- Presentation to the Royal Society of Canada Expert Panel on The Status and Future of Canada's Libraries and Archives in November 2013 in Regina. The Board also compiled a brief with inputs from each library sector for submission to the panel.

- 2014-15

o Partnered with SLA to champion and promote The Partnership's Continuing Education Certificate Program

o Coordinated province-wide One Book, One Province initiative

o Spearheaded Saskatchewan Libraries joining the Library Toolshed (a collaborative initiative supported by The Alberta Library, Association of BC Public Library Directors, and the Manitoba Public Library Services 
Partnership: The Canadian Journal of Library and Information Practice and Research, vol. 10, no. 2 (2015)

Branch), a site for library training, program guides, sharing resources, and discussing services 